\title{
Potensi The Ogoh-Ogoh Bali Collection Sebagai Atraksi Wisata Budaya Di Desa Mengwi Kabupaten Badung
}

I Wayan Nanendra Dama Gunawana, 1, I Made Bayu Ariwangsaa, 2

1nanendradamagunawan@gmail.com,2bayu_ariwangsa@unud.ac.id

a Program Studi S1 Destinasi Pariwisata, Fakultas Pariwisata,Universitas Udayana, Jl. Dr. R. Goris, Denpasar, Bali 80232 Indonesia

\section{Abstract}

The Ogoh-ogoh Bali Collection is a center place to preserve one of the Balinese traditions that is "OgohOgoh", which is also seen as a small monument to preserve the culture as well as supporting tourism, especially cultural tourism. The Ogoh-Ogoh Bali Collection is located in Mengwi village, Badung regency, which has the great potential of cultural tourism in the form of cultural collections and interesting attraction for tourists. Based on these assumptions the background study of the topic chosen has raised concerns about the potential The Ogoh-Ogoh Bali Collection and obstacles faced in the management of cultural tourism attractions.

Types and sources of data used are qualitative, primary and secondary data. Data collection is conducted by observation, interview, documentation, literature study, research instrument in the form of guide lines for the interview. Analysis of the data used is descriptive qualitative data analysis using a matrix approach to the concept of $4 A$ and SWOT analysis.

These results indicate that the potential of the Ogoh-Ogoh Bali is quite large, in addition to have a collection that contains the value of history, art and culture, and spiritual, The Ogoh-Ogoh Bali also has a show or attraction called "The Ogoh-Ogoh Dance". Although the potential of theOgoh-Ogoh Bali is quite large, but to date, there are still many experienced constraints that must be resolved. Thus, that the Vision and Mission of the program from the manager of TheOgoh-Ogoh Bali can be implemented.

\section{Keywords: Potential, Ogoh-Ogoh, Tourist Attraction, Cultural Tourism}

\section{PENDAHULUAN}

Ada banyak alasan mengapa orang berwisata ke suatu daerah, beberapa yang paling umum adalah untuk melihat keseharian penduduk setempat, menikmati keindahan alam, menyaksikan budaya yang unik, atau mempelajari sejarah daerah tersebut. Atraksi wisata merupakan komponen yang signifikan dalam menarik wisatawan. Suatu daerah atau tempat hanya dapat menjadi tujuan wisata kalau kondisinya sedemikian rupa,sehingga ada yang dapat dikembangkan menjadi atraksi wisata. Dalam tipe wisata budaya (cultural tourism) orang tidak hanya sekedar mengunjungi suatu tempat untuk menyaksikan dan menikmati atraksi, mungkin sengaja datang utuk mempelajari tentang keadaan setempat (Geria:1995).

Bagi Indonesia pariwisata memiliki peranan yang sangat besar sebagai salah satu sumber penerimaan devisa alternative di dalam pembangunan nasional dikatakan demikian karena Indonesia yang memiliki kekayaan alam, budaya dan adat-istiadat yang berbeda yang merupakan modal utama dalam kepariwisataan. Salah satunya yaitu daerah Bali yang merupakan daerah tujuan wisata di Indonesia karena secara geografis daerah Bali letaknya sangat strategis, yakni di tengah-tengah kepulauan Indonesia dan daerah Bali memiliki keindahan alam dan budaya yang sangat bagus serta adat istiadat yang khas sehingga mampu menjadi daya tarik bagi wisatawan. Kabupaten Badung adalah sebuah kabupaten yang terletak di provinsi Bali. Selain sebagai pusat kota,Mengwi juga terkenal dengan Pura Taman Ayun,tepat di jalurPura Taman Ayun terdapat salah satu potensi wisata yang sangat menarik untuk dikunjungi oleh wisatawan yaitu The Ogoh-ogoh Bali Collection.The Ogoh-ogoh Bali merupakan sebuah tempat yang disediakan untuk melestarikan salah satu tradisi Bali yaitu "Ogoh-Ogoh" dan juga dipandang sangat penting untuk memonumenkan sebagian kecil upaya untuk ikut melestarikan kebudayaan Bali dan menunjang pariwisata khususnya di Desa Mengwi,Kabupaten Badung.

Penelitian ini memiliki tujuan, untuk mengetahui potensi The Ogoh-Ogoh Bali Collection dan untuk mengetahui kendala yang dihadapi pengelola The Ogoh-Ogoh Bali Collection sebagai atraksi wisata budaya.Hasil penelitian ini diharapkan dapat dijadikan bahan masukan atau sumbangan pemikiran dan informasi bagi pengelola objek wisata The Ogoh-Ogoh Bali Collection dan lebih memperkenalkan ogoh-ogoh kepada masyarakat dunia. 


\section{TINJAUAN PUSTAKA}

Konsep dan teori analisis yang digunakan dalam penelitian ini,antara lain konsep pariwisata(UU No.10 Tahun 2009), konsep potensi wisata(Yoeti,1992), konsep atraksi wisata(Mahadewi,2004), konsep tentang komponen pariwisata(Pitana,2008), konsep pariwisata budaya merupakan perjalanan yang dilakukan atas dasar keinginan untuk memperluas pandangan hidup seseorang dengan jalan mengadakan kunjungan atau peninjauan ke tempat lain atau keluar negeri,mempelajari keadaan rakyat, kebiasaan,dan adat istiadat mereka,cara hidup mereka,budaya dan seni mereka(Anom,2005). Serta menggunakan teori analisis SWOT yang merupakan salah satu metode untuk menggambarkan kondisi dan mengevaluasi suatu masalah, proyek atau konsep berdasarkan faktor internal (dalam) dan faktor eksternal (luar) yang terdiri dari Strengths(kekuatan), Weakness (kelemahan), Opportunities (peluang) dan Threats (ancaman) (Rangkuti,2005).

\section{METODE}

Jenis data dan sumber data yang digunakan yaitu data kualitaif, data primer dan data sekunder.Teknik Pengumpulan data dilakukan dengan cara observasi, wawancara mendalam, dokumentasi, studi kepustakaan, instrument penelitian berupa pedoman wawancara.Teknik Penentuan informan pada penelitian ini menggunakan purposive sampling.Penentuan informan dimulai dengan menentukan informan pangkal.Teknik Analisis data yang digunakan adalah analisis data deskriptif kualitatif dengan menggunakan komponen 4A Pariwisata dan matriks analisis SWOT yaitu memaparkan dengan jelas hasil temuan berdasarkan permasalahan yang diteliti dengan sumber data yang akurat.

\section{HASIL DAN PEMBAHASAN \\ 4.1 Hasil}

The Ogoh-ogoh Bali merupakan sebuah tempat yang didedikasikan untuk melestarikan salah satu tradisi Bali yaitu "ogoh-ogoh" yang menyimpan sekitar 32 buah ogoh-ogoh dari berbagai daerah di Bali khususnya Kabupaten Badung. The Ogoh-ogoh Bali terletak di jalan Ayodhya, BanjarPande, Desa Mengwi,Kabupaten Badung, tepatnya di sebelah barat obyek wisata Pura Taman Ayun, tempat ini terlihat jelas dari
Taman Ayun ditandai dengan spanduk besar yang bertuliskan "The Ogoh-Ogoh Bali Collection".

Tempat ini dikelola oleh seorang seniman asli desa Mengwi yang bernama I Ketut Nuada. Beliau adalah seorang pelukis di dalam kompleks Pura Taman Ayun dan merupakan orang pertama yang memiliki gagasan untuk mendirikan The Ogoh-Ogoh Bali Collection. Ide/gagasan beliau membuka tempat ini karena rasa keperihatinan melihat banyak ogoh-ogoh yang ditelantarkan di sepanjang jalan setelah hari raya penyepian,karena menurut beliau ogoh-ogoh adalah karya seni dan suatu kreatifitas yang memiliki tinggi yang wajib dilestarikan.

\subsection{Pembahasan}

\subsubsection{Potensi The Ogoh-Ogoh Bali Collection} dilihat dari konsep 4A

Disini dijelaskan potensi yang ada menurut skema konsep 4A (attraction, accessbilities, amenities dan ancillary).

\section{Attraction (Atraksi)}

Atraksi wisata yang dimaksudkan disini adalah

- Koleksi The Ogoh-Ogoh Bali Collection

- Pementasan tarian ogoh-ogoh (The Ogoh-Ogoh Dance)

\section{Accessbilities(Aksesbilitas)}

Aksebilitas adalah tingkat kemudahan untuk menuju objek wisata The Ogoh-Ogoh BaliCollection. Tingkat aksebilitas diukur dari:

- Jenis alat transportasi

- Keadaan jalan

\section{Amenities (Fasilitas)}

Fasilitas yang ada di The Ogoh-Ogoh Bali Collection adalah sebagai berikut:

- Ruang Pameran Tetap

- Layar/TV LED untuk menampilkan pementasan ogoh-ogoh waktu hari raya Pengerupukan dan tarian ogoh-ogoh dance dari The Ogoh-Ogoh Bali

- Toilet

- Buku panduan tentang The Ogoh-Ogoh Bali

- Stage/tempat pementasan ogoh-ogoh dance

- Tempat Parkir

4. Ancillary (Kelembagaan dan Sumber Daya Manusia pendukung kepariwisataan)

- Manajemen The Ogoh-Ogoh Bali Collection

- Sumber Daya Manusia(SDM) yang mengelola The Ogoh-Ogoh Bali Collection

- Peranan Pemerintah

\subsubsection{Potensi The Ogoh-Ogoh Bali Collection Menurut Analisis SWOT}


Analisis SWOT ini didasarkan pada logika yang dapat memaksimalkan kekuatan (strength) dan peluang (oppurtunities),namun secara bersamaan dapat meminimalkan kelemahan (weakness) dan ancaman (threats) dalam kondisi yang ada saat ini dalam usaha pengelolaan atraksi wisata budaya pada The Ogoh-Ogoh Bali Collection.Selain itu,analisis ini digunakan untuk mengkaji dan mengindentifikasi kondisi dan keadaan The Ogoh-Ogoh Bali Collection.Berikut ini diuraikan pendekatan SWOT pada The OgohOgoh Bali:

\section{Kekuatan (Strenght)}

Kekuatan yang dimaksud adalah segala sesuatu yang berpotensi sebagai andalan The Ogoh-Ogoh Bali.Kekuatan tersebut terdiri atas:

1. Koleksi-Koleksi The Ogoh-Ogoh Bali The Ogoh-Ogoh Bali mengoleksi sekitar 32 ogoh-ogoh yang didapatkan pengelola dari seluruh wilayah di Bali,khususnya Kabupaten Badung yang memiliki cerita atau filosofi tentang Hindu centre.

2. The Ogoh-Ogoh Bali Collection merupakan tempat mengoleksi ogoh-ogoh pertama didirikan di Bali,khususnya di Kabupaten Badung.

3. Kesenian

"The Ogoh-OgohDance" (TarianOgohOgoh) merupakan sebuah garapan pertunjukan yang dimiliki oleh The OgohOgoh Bali bekerjasama dengan Sanggar Daduantari.

4. Media Informasi

Untuk mengetahui tentang keberadaan dan koleksi yang ada di The Ogoh-Ogoh Bali sudah disediakan brosur The OgohOgoh Bali "Bali Art and Culture Tourism", brosur ini bisa didapatkan secara gratis. Informasi tentang The Ogoh-Ogoh Bali juga bisa dapat diakses melalui situs Internet:www.ogoh-ogohbali.com.

Sebelumnya The Ogoh-Ogoh Bali juga pernah dipromosikan oleh TV lokal Bali,yaitu Bali TV.

5. Tarif Masuk

Setiap pengunjung museum dikenakan tarif masuk yang murah dan terjangkau.

\section{Kelemahan(Weakness)}

1. Sarana dan Prasarana

- The Ogoh-Ogoh Bali Collection belum menerapkan komponen dasar yang dijelakan sebagai berikut:
- Pola arus (sirkulasi) pengunjung belum mengikuti tata letak (lay-out) yang logis.

- Lokasi serta tata letak The Ogoh-Ogoh bali Colection yang kurang sedikit diperluas.

- Juga terbatasnya fasilitas yang tersedia di The Ogoh-Ogoh Bali,seperti bangku duduk untuk wisatawan.

- Belum adanya kerjasama dengan industri-industri pariwisata, seperti Travel Agent.

2. Sumber Daya Manusia

Komposisi SDM(sumber daya manusia) yang perlu dioptimalkan lagi,dimana hanya ada pemilik The Ogoh-Ogoh Bali Collection yang dapat melakukan kegiatan pemasaran.

3. Belum adanya kerjasama antara pihak pengelola dengan pihak travel agent untuk mendatangkan wisatawan.

\section{Peluang (Oppurtunities)}

1. Kedekatan dengan objek lain

The Ogoh-Ogoh Bali memiliki letak yang cukup dekat atau berdampingan dengan objek wisata lainnya,seperti Pura Taman Ayun.

2. Sumber Daya Manusia

Dengan memberikan pembinaan melalui pendidikan pemasaran dan pelatihan pariwisata kepada staf pengelola The Ogoh-Ogoh Bali Collection sehingga lebih berkualitas dan kompeten di bidang pemasaran dan pariwisata.

3. Meningkatkan kecintaan masyarakat terhadap seni dan budaya. Dengan didirikannya The Ogoh-Ogoh Bali Collection sebagai atraksi budaya, diharapakan dapat memberi kontribusi langsung kepada pemuda atau masyarakat setempat dalam hal berkreatifitas.

\section{Ancaman(Threats)}

1. Sosial Budaya Masyarakat

Persaingan kesenian serta kebudayaan modern serta seiring majunya zaman dan teknologi,mengakibatkan eksploitasi terhadap kesenian dan kebudayaan tradisional. Sehingga memungkinkan di kawasan The Ogoh-Ogoh Bali Collection terjadinya komersialisasi budaya. 
2. Sistem pemeliharan The Ogoh Ogoh Bali Collection yang sangat kurang diperhatikan dapat mengakibatkan dampak negative seperti kerusakan, pencemaran, dan kehilangan akibat kriminalitas.

3. Sedikit wisatawan yang baru mengetahui keberadaan The Ogoh-ogoh Bali Collection.
Kondisi The Ogoh-Ogoh Bali Collection sebagai Atraksi Wisata Budaya Di Desa Mengwi,Kabupaten Badung berdasarkan tabel matrik SWOT yang akan dijelaskan sebagai berikut:

TABEL 1. MATRIK SWOT THE OGOH-OGOH BALI COLLECTION

\begin{tabular}{|c|c|c|}
\hline KF A S & $\begin{array}{l}\text { Kekuatan (S) } \\
\text { 1. Koleksi-koleksi The Ogoh-Ogoh Bali } \\
\text { Collection yang kaya nilai seni - } \\
\text { budaya, sejarah, dan memiliki } \\
\text { fungsi spiritual } \\
\text { 2. Garapan pertunjukan/atraksi The } \\
\text { Ogoh-Ogoh Dance } \\
\text { 3. The Ogoh-Ogoh Bali Collection } \\
\text { merupakan museum atau tempat } \\
\text { mengoleksi ogoh-ogoh pertama } \\
\text { didirikan di Bali } \\
\text { 4. Berada di kawasan Pura Taman } \\
\text { Ayun, yang merupakan pusat } \\
\text { pariwisata Desa Mengwi } \\
\text { 5. Kegiatan sosial masyarakat } \\
\text { 6. Aksesbilitas yang memadai } \\
\text { 7. Tarif masuk yang terjangkau }\end{array}$ & $\begin{array}{l}\text { Kelemahan (W) } \\
\text { 1. Pola arus (sirkulasi) pengunjung yang } \\
\text { mengikuti tata letak(lay out) belum ada } \\
\text { 2. Lokasi dan dan tata letak koleksi yang } \\
\text { terlalu sempit dan tumpang tindih } \\
\text { 3. Keamanan koleksi The Ogoh-Ogoh Bali } \\
\text { Collection serta pengunjung yang kurang } \\
\text { terjamin } \\
\text { 4. SDM yang rendah } \\
\text { 5. Belum adanya kerjasama dengan travel } \\
\text { agent }\end{array}$ \\
\hline $\begin{array}{l}\text { Peluang }(\mathbf{0}) \\
\text { 1. Kedekatan dengan objek wisata } \\
\text { lain } \\
\text { 2. Meningkatkan kecintaan } \\
\text { masyarakat terhadap seni dan } \\
\text { budya serta berkretifitas }\end{array}$ & $\begin{array}{l}\text { STRATEGI (SO) } \\
\text { 1. Menjaga dan melestarikan koleksi } \\
\text { The Ogoh-Ogoh Bali Collection } \\
\text { sebagai sumber sejarah,seni- } \\
\text { budaya, dan spiritual } \\
\text { 2. Aksesbilitas yang memadai } \\
\text { sehingga memudahkan kunjungan } \\
\text { wisatawan } \\
\text { 3. Atraksi The Ogoh-Ogoh dance } \\
\text { sebagai penarik kunjungan } \\
\text { wisatawan }\end{array}$ & $\begin{array}{l}\text { STRATEGI (WO) } \\
\text { 1. Meningkatkan keamanan baik di dalam } \\
\text { maupun di luar kawasan The Ogoh-ogoh } \\
\text { Bali Collection } \\
\text { 2. Memperbaiki teknis penataan dan } \\
\text { pemajangan koleksi The Ogoh-Ogoh Bali } \\
\text { Collection } \\
\text { 3. Meningkatkan promosi tentang koleksi } \\
\text { The Ogoh-Ogoh Bali Collection yang kaya } \\
\text { dengan nilai sejarah,seni budaya dan } \\
\text { spiritual kepada masyarakat luas }\end{array}$ \\
\hline 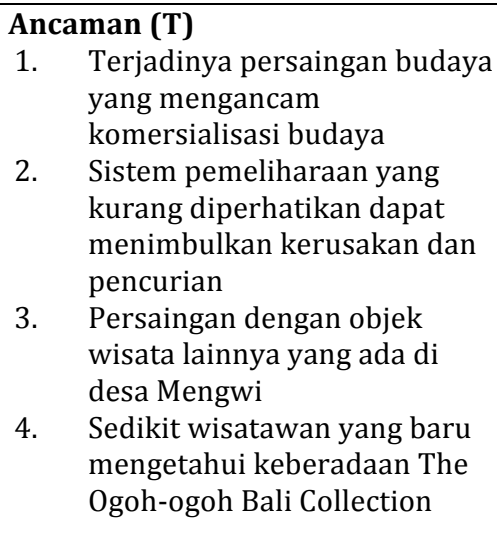 & $\begin{array}{l}\text { STRATEGI (ST) } \\
\text { 1. Meningkatkan sistem pemeliharan } \\
\text { The Ogoh-Ogoh Bali Collection } \\
\text { 2. Meningkatkan informasi dan } \\
\text { promosi melalui media informasi } \\
\text { dan jaringan yang lebih luas lagi } \\
\text { 3. Mengenal lebih dalam kekayaan } \\
\text { sejarah,seni-budaya The Ogoh-Ogoh } \\
\text { Bali Collection untuk mengaktifkan } \\
\text { organisasi tradisional yang ada di } \\
\text { kawasan The Ogoh-Ogoh Bali } \\
\text { Collection }\end{array}$ & $\begin{array}{l}\text { STRATEGI (WT) } \\
\text { 1. Meningkatkan sistem pemeliharaan } \\
\text { The Ogoh-Ogoh Bali Collection } \\
\text { 2. Meningkatkan SDM pengelola The } \\
\text { Ogoh-Ogoh Bali Collection } \\
\text { 3. Mengantisipasi persaingan The Ogoh- } \\
\text { Ogoh Bali Collection dengan objek } \\
\text { wisata lainnya }\end{array}$ \\
\hline
\end{tabular}

Sumber: Hasil Penelitian 2015

\section{Strategi SO}

a. Menjaga dan melestarikan koleksi The OgohOgoh Bali Collection yang memiliki nilai sejarah,seni-budaya,dan spiritual (S) , sehingga menumbuhkan dan kecintaan pada sejarah dan seni-budaya dan berkreatifitas (0) 
b. Aksesbilitas yang memadai (S), sehingga memudahkan kunjungan wisatawan ke The Ogoh-Ogoh Bali Collection dan ke objek wisata lain yang mempunyai jarak yang dekat satu sama lain (0)

c. The Ogoh-Ogoh Bali Collection merupakan museum atau tempat mengoleksi ogoh-ogoh pertama didirikan di Bali dan adanya atraksi The Ogoh-Ogoh dance yang mampu menarik minat wisatwan untuk berkunjung (S)

\section{Strategi ST}

a. Menjaga dan melestarikan koleksi The OgohOgoh Bali Collection yang memiliki nilai sejarah,seni-budaya, dan spiritual (S), untuk mengantisipasi adanya persaingan dengan objek wisata lainnya (T)

b. Meningkatkan sistem pemeliharaan The Ogoh-Ogoh Bali Collection (S), untuk mengurangi resiko kerusakan dan hilangnya koleksi akibat tindakan kriminalitas (T)

c. Meningkatkan promosi dan informasi mengenai potensi-potensi The Ogoh-Ogoh Bali Collection (S), melalui media informasi agar lebih dikenal masyarakat luas $(\mathrm{T})$

\section{Strategi WO}

a. Meningkatkan keamanan baik di dalam maupun di luar kawasan The Ogoh-Ogoh Bali Collection (W), sehingga dapat meningkatkan minat wisatawan berkunjung (0)

b. Memperbaiki teknis penataan dan pemajangan koleksi The Ogoh-Ogoh Bali Collection (W), demi kenyamanan dan kualitas kunjungan (O)

c. Meningkatkan promosi tentang koleksi sejarah dan seni-budaya yang ada di The Ogoh-Ogoh Bali Collection (W) kepada masyarakat luas (0)

d. Melakukan kerjasama dengan pihak travel agent (W), bahwa The Ogoh-Ogoh Bali Collection memiliki pertunjukan/atraksi yang sangat menarik ditonton oleh wisatawan 0)

3. Strategi WT

a. Meningkatkan sistem pemeliharaan The Ogoh-Ogoh Bali Collection (W) sehingga dapat menghindari kerusakan dan terjadinya kriminalitas (T)

b. Meningkatkan peningkatan SDM pengelola (W), sehingga siap menghadapi perkembangan dunia kepariwisataan yang terus maju ( $\mathrm{T}$ )

c. Memperbaiki dan menjaga sarana dan prasarana (W), sehingga mengantisipasi persaingan dengan The Ogoh-Ogoh Bali Collection dengan objek wisata lainnya (T)

d. Melakukan kerjasama dengan pihak travel agent (W), agar wisatawan dapat mengetahui keberadaan The Ogoh-Ogoh Bali Collection (T).

\subsubsection{Kendala-kendala yang dihadapi pengelola The Ogoh-Ogoh Bali Collection sebagai Atraksi Wisata Budaya}

Berdasarkan hasil analisis SWOT yang diperoleh pada tabel matriks SWOT, maka potensiThe Ogoh-ogoh Bali Collection menghadapi kendala-kendala,yakni:

1. Pembangunan gedung yang belum terealisasi.

2. Minimnya promosi yang dilakukan oleh pengelola dan perintah daerah.

3. Keamanan di dalam maupun luar The OgohOgoh Bali Collection yang kurang.

4. Kurang optimalnya kualitas Sumber Daya Manusia yang ada di The Ogoh-Ogoh Bali Collection.

5. Belum adanya kerjasama dengan industri pariwisata/pihak travel agent dengan pihak pengelola The Ogoh-Ogoh Bali Collection.

Sesuai dengan kendala-kendala yang dihadapi maka sasaran yang harus dicapai guna mewujudkan The Ogoh-Ogoh Bali Collection sebagai Atraksi Wisata Budaya yang dapat mendukung kepariwisataan Desa Mengwi, Kabupaten Badung adalah sebagai berikut:

1. Memperbaiki sarana dan prasarana The Ogoh-Ogoh Bali Collection

2. Menyediakan media informasi dan meningkatkan promosi

3. Meningkatkan kualitas Sumber Daya Manusia

4. Meningkatkan keamanan baik dari dalam maupun luar dengan menambah jumlah petugas keamanan dengan waktu dan tanggung jawab yang sesuai dengan kebutuhan.

5. Melakukan kerjasama antara pihak pengelola dengan pihak travel agent, agar wisatawan mengetahui keberadaan dari The Ogoh-Ogoh Bali Collection dan menyaksikan atraksi dari The Ogoh-Ogoh Dance yang memotivasi minat wisatawan untuk berkunjung. 


\section{SIMPULAN DAN SARAN}

\subsection{Simpulan}

The Ogoh-Ogoh Bali Collection memiliki potensi yang cukup besar untuk menjadi sebuah atraksi wisata budaya,selain dari koleksi-koleksi yang mencakup banyak nilai,seperti: filosofi,seni budaya, dan fungsi spiritual.

Meskipun The Ogoh-Ogoh Bali Collection memiliki potensi yang cukup besar, namun hingga kini masih menghadapi banyak kendala antara lain, pembangunan gedung yang belum terealisasi, minimnya promosi yang dilakukan oleh pengelola dan pemerintah, belum adanya kerjasama dengan pihak terkait seperti travel agent, keamanan di dalam maupun diluar yang kurang, dan kurang optimalnya kualitas Sumber Daya Manusia yang ada di The Ogoh-Ogoh Bali Collection.

\subsection{Saran}

Saran yang bisa diberikan mengenai potensi The Ogoh-Ogoh Bali Collection sebagai atraksi wisata budaya sebgai berikut:

- Mendorong pemerintah agar dapat dengan cepat membantu mendukung realisasi pembangunan gedung The Ogoh-Ogoh Bali Collection.

\section{DAFTAR PUSTAKA:}

Anom,I Putu.2005."Evaluasi Terhadap Pengembangan Potensi Kawasan Pura Luhur Batukaru sebagai Daya Tarik Wisata Budaya dan Alam di Desa WongayaGede Kabupaten Tabanan".Sebuah artikel dalam Majalah Analisis Pariwisata Volume 6

Damardjati,RS.1998.Istilah-Istilah Dunia Pariwisata.Jakarta.PT. Pradnya Paramita.

Geria,Wayan.1995.Pariwisatadan Dinamika Kebudayaan Lokal,Nasional,Global. Denpasar.Upada Sastra.

Gunawan,Imam.2013.Metode Penelitian Kualitatif Teori dan Praktik.Jakarta. Bumi Aksara.

Indrayana, I Kadek.2010."Potensi Wisata Komunitas Gabungan Anak Seni Sesetan (GASES) Sebagai Atraksi Wisata Budaya"

Mahadewi. 2004. Kriteria Atraksi Wisata di Bali. Denpasar. Udayana University Press

Moleong, Lexy J.2005. Metodelogi Penelitian Kualitatif. Bandung : Rosdakarya.

Pendit,Nyoman S.1999.Ilmu Pariwisata(Sebuah Pengantar Perdana).Jakarta.Pradnya Paramita.

Pitana,IGede.2008.Ilmu Pariwisata Sebagai Ilmu yang Mandiri.Makalah Seminar Nasional Kerjasama Universitas Udayana dengan Depbudpar RI.Denpasar.

Rangkuti,Freddy.2005.Analisis SWOT Teknik Membedah Kasus Bisnis.Jakarta.Gramedia.

Sari,Okiana Nur Indah.2006. "Pengembanagan Potensi Museum Wayang Indonesia Sebagai Atraksi Wisata Wisata Budaya Di Kabupaten Wonogiri"
- Menambah dan melangkapi sarana dan prasarana pariwisata untuk memberikan kenyamanan kepada wistawan.

- Melakukan kerjasama dengan pihak-pihak terkait,sepeti travel agent.

- Mengembangkan paket wisata terpadu antara The Ogoh-Ogoh Bali Collection sebagai atraksi wisata budaya dengan objek wisata lainnya di Desa Mengwi.

- Perlu adanya tenaga teknis yang ahli dalam merawat koleksi-koleksi di The Ogoh-Ogoh Bali Collection.

- Meningkatkan keamanan baik di dalam maupun luar The Ogoh-Ogoh Bali Collection.

- Penyediaan souvenir khas The Ogoh-Ogoh Bali Collection.

- Meningkatkan kualitas Sumber Daya Manusia dengan cara memberikan pelatihan bahasa dan kepariwisatan kepada pihak pengelola The Ogoh-Ogoh Bali Collection agar dapat memberikan informasi yang baik dan jelas kepada pengunjung domestik maupun mancanegara.

- Pelajar SD-SMA diwajibkan mengunjungi The Ogoh-Ogoh Bali Collection untuk nilai kreatifitas,nilai seni-budaya,dan sejarah.

Shadily,Hasan. 2000. Kamus Besar Bahasa Indonesia jilid II. Jakarta. Gramedia.

Sugiyono.2008.Metode dan Teknik Pengumpulan Data Dalam Penelitian Kualitatif.Jakarta.Gramedia Pustaka Utama.

Sukarsa,I Made.1994.Pengantar Pariwisata.Departemen Pendidikan dan Kebudayaan Direktorat Jenderal Pendidikan Tinggi Badan Kerjasama Perguruan Tinggi NegeriIndonesia Timur.

Suwantoro, Gamal. 1997. Dasar-Dasar Pariwisata.Yogyakarta.ANDI

Suwena \& Widyatmaja. 2011.Pengantar Dasar Ilmu Pariwisata.Denpasar.UdayanaUniversity Press

Undang-Undang Republik Indonesia No.10 Tahun 2009 tentang Kepariwisataan

Yoeti, Oka A.1992.Pengantar ilmu pariwisata.Bandumg Angkasa

Yoeti, Oka A.1999.Perencanaan dan pengembangan pariwisata.Jakarta : PT . pradnya paramita.

Yoeti, Oka A1999.Psikologi pelayanan wisata. Jakarta. 